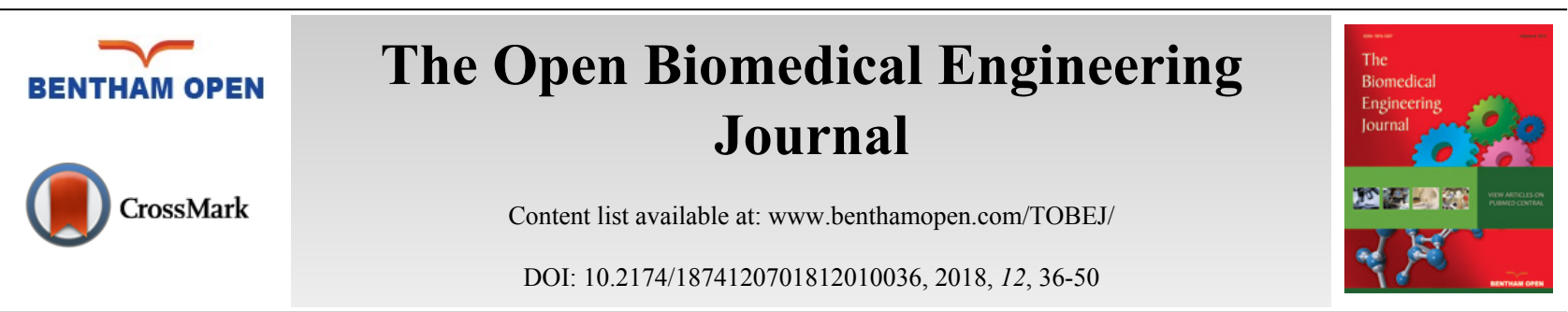

RESEARCH ARTICLE

\title{
Investigating the Conformation of S100ß Protein Under Physiological Parameters Using Computational Modeling: A Clue for Rational Drug Design
}

Elvis K. Tiburu ${ }^{1,3, *}$, Ibrahim Issah ${ }^{1}$, Mabel Darko ${ }^{1}$, Robert E. Armah-Sekum ${ }^{1}$, Stephen O. A. Gyampo $^{1}$, Nadia K. Amoateng ${ }^{1}$, Samuel K. Kwofie ${ }^{1,2,3}$ and Gordon Awandare ${ }^{2,3}$

${ }^{I}$ Department of Biomedical Engineering, College of Basic and Applied Sciences, University of Ghana, P. O. Box LG 25, Legon

${ }^{2}$ Department of Biochemistry, Cell and Molecular Biology, University of Ghana, P. O. Box LG 25, Legon

${ }^{3}$ West African Centre for Cell Biology of Infectious Pathogens, University of Ghana, P. O. Box LG 25, Legon

Received: April 20, 2018

Revised: May 23, 2018

Accepted: June 2, 2018

Abstract:

Background:

Physiochemical factors such as temperature, $\mathrm{pH}$ and cofactors are well known parameters that confer conformational changes in a protein structure. With $\mathrm{S} 100 \beta$ protein being a metal binding brain-specific receptor for both extracellular and intracellular functions, a change in conformation due to the above-mentioned factors, can compromise their cellular functions and therefore result in several pathological conditions such as Alzheimer's disease, Ischemic stroke, as well as Myocardial Infarction.

\section{Objective:}

The studies conducted sought to elucidate the effect of these physiological factors on the conformational dynamics of S100 $\beta$ protein using computational modeling approaches.

\section{Method:}

Temperature-dependent and protein-cofactor complexes molecular dynamics simulations were conducted by varying the temperature from 100 to $400 \mathrm{~K}$ using GROMACS 5.0.3. Additionally, the conformational dynamics of the protein was studied by varying the $\mathrm{pH}$ at 5.0, 7.4 and 9.0 using Ambertools17. This was done by preparing the protein molecule, solvating and minimizing its energy level as well as heating it to the required temperature, equilibrating and simulating under desired conditions (NVT and NPT ensembles).

\section{Results:}

The results show that the protein misfolds as a function of increasing temperature with alpha helical content at $100 \mathrm{~K}$ and $400 \mathrm{~K}$ being $57.8 \%$ and $43.3 \%$, respectively. However, the binding sites of the protein were not appreciably affected by temperature variations. The protein displayed high conformational instability in acidic medium $(\mathrm{pH} \sim 5.0)$. The binding sites of $\mathrm{Ca}^{2+}, \mathrm{Mg}^{2+}$ and $\mathrm{Zn}^{2+}$ were identified and each exhibited different groupings of the secondary structural elements (binding motifs). The secondary structure analysis revealed different conformational changes with the characteristic appearance of two beta hairpins in the presence of $\mathrm{Zn}^{2+}$ and $\mathrm{Mg}^{2+}$.

\section{Conclusion:}

High temperatures, different cofactors and acidic $\mathrm{pH}$ confer conformational changes to the $\mathrm{S} 100 \beta$ structure and these results may indicate the design of novel drugs against the protein.

\footnotetext{
"Address correspondence to this author at the Department of Biomedical Engineering, College of Basic and Applied Sciences, University of Ghana, Legon, Ghana; Tel: +233559585194; E-mail: etiburu@ug.edu.gh
} 
Keywords: S100ß Protein, Molecular Dynamics, Cofactors, Energy Minimization, Physiological Parameters, Alzheimer's.

\section{INTRODUCTION}

\subsection{Background}

$\mathrm{S} 100 \beta$ protein is a metal-binding receptor located in the metal ion-rich synaptic regions of the human brain. At the onset of any neurodegenerative disorders such as Alzheimer's, Down's syndrome, trauma, brain injury, myocardial infarction and stroke, there is an increase in the concentration of $\mathrm{S} 100 \beta$ proteins which serves as a biomarker for clinical purposes [1]. The presence of metal ions in physiological environment makes metal-binding a necessary proviso for triggering conformational changes which ultimately can result in biological activity $[2,3]$. Conformational changes in proteins refer to an alteration in the tertiary structure of the protein influenced by physiochemical conditions such as temperature, $\mathrm{pH}$ and ionic binding $[4,5]$. The failure of $\mathrm{S} 100 \beta$ protein to maintain its native functional threedimensional (3D) conformation has been linked to pathological conditions known as neurodegenerative disorders [6] (Fig. 1). Although native S100 $\beta$ has two helix-loop-helix calcium binding structural motifs, under unfavourable physiochemical conditions (i.e. temperature, $\mathrm{pH}$ and cofactors), these proteins experience a change in their native 3D structure [7].

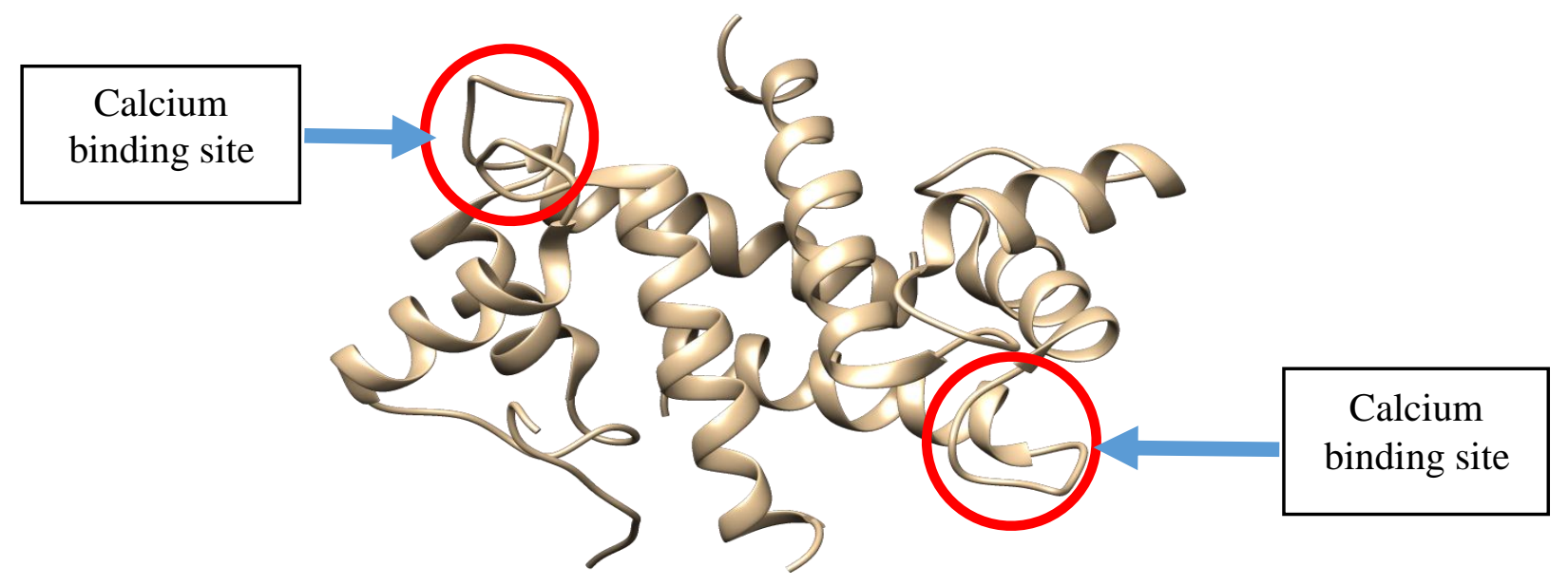

Fig. (1). A PyMol representation of the native structure of S100 $\beta$ protein (PDB ID: 5D7F), depicting the two calciumbinding sites circled in red colour.

The protein is a member of the family of calcium-binding proteins known as the S100 family [8, 9]. The biological function of these proteins is regulated when bound to calcium ions. The family consists of 25 members which are functionally categorized into three groups: those that perform intracellular regulatory effects, extracellular regulatory effects as well as the combination of the two [10]. The members of this family are considered to be low molecular weight proteins with an average monomer molecular weight of around 12-14 kDa but 21-23 kDa in its homodimer structure. They are specifically found in vertebrates, suggesting that they are evolutionarily young [11].

S100 $\beta$ proteins are basically characterized by two EF-hand (pseudo and typical EF-hand) calcium active binding motifs and so undergoes a large conformational change upon binding with calcium. However, it has been shown that the pseudo-EF-hand has minor structural changes when $\mathrm{Ca}^{2}+$ binds whereas the typical has a large repositioning of several side chain oxygen ligand during $\mathrm{Ca}^{2+}$ coordination (EF-2: D61-E72). Several target structures have been exploited including $\mathrm{Zn}^{2+}$ site in $\mathrm{S} 100 \beta$ inhibition which is relevant in drug design, hence can mimic target binding which can enhance $\mathrm{Ca}^{2+}$ binding affinity. This exposes the hydrophobic residues and results in protein-protein interaction affecting biological activities in the cellular environment.

A typical dimeric S100-target interaction is $\mathrm{Ca}^{2+}$ - dependent and involves at least 11 possible states, 13 dissociation constants, 4 conformational changes and the corresponding rate constants, per symmetric subunit. Furthermore, $\mathrm{Ca}^{2+}$ binding to S100 $\beta$ causes conformational changes and the binding events for a single target are symmetric and occur independently of those on the other subunit, thereby making it interesting to consider one S100 $\beta$ subunit in 
thermodynamic scheme [12].

These proteins also show a high degree of specialization by their cell-specific expression patterns. For instance, $\mathrm{S} 100 \beta$ is brain-specific while $\mathrm{S} 100 \alpha 1$ is restricted to cardiomyocytes and cells of the kidney only. S100 $\beta$ proteins are characterized by two calcium-binding active sites and the name S100 is coined because they are soluble in $100 \%$ saturated ammonium sulphate at neutral $\mathrm{pH}[10,11]$. Exogenous $\mathrm{S} 100 \beta$ excite the survival of neurons together with neuritis extension which can affect learning and memory in a chemical regulatory (paracrine, autocrine, endocrine) manner [13]. S100 $\beta$ also plays a role as a mediator of glial-neuronal interactions to enhance brain development and synaptic transmission possibly through G-protein coupled receptor (GPCR). Furthermore, they play a role in raising intracellular calcium concentrations either by dependent $\mathrm{Ca}^{2+}$ - channels or by depletion of the calcium stores [14]. At the molecular level, S100 $\beta$ proteins modulate several biological activities such as calcium homeostasis, protein phosphorylation, motility, energy metabolism, maintenance of cytoskeleton dynamics, cell growth, as well as regulation of cell proliferation, inflammation, conduction and transmission of nerve impulses $[15,16]$.

Temperature variations disrupt hydrogen bonds and non-polar hydrophobic interactions of a protein due to increase in its molecular kinetic energy. This may lead to denaturing of the protein. Thus, temperature variations confer unique conformational changes and alter the biological activities of the protein. Additionally, the pH dependent property through the $\mathrm{pKa}$ values of the protonated residues of the protein confers different conformational dynamics to the S100 $\beta$ protein. Much more, biological activities of proteins are mostly modulated by small molecules (cofactors or ligands). Upon ligand or cofactor binding, a receptor undergoes a structural change which triggers a specific biological response that may be critical to the functions of an organism at the cellular and molecular level [17]. For example, the process of phosphorylation activates or deactivates a receptor thereby altering its biological activity. The binding affinity between a cofactor and a protein as well as its specific residues at the binding motifs play a pivotal role in the conformational dynamics of the protein [18]. In this study, computational modeling approaches were used to predict the conformational changes of $\mathrm{S} 100 \beta$ protein at varying physiological conditions such as temperature, $\mathrm{pH}$ and cofactors. Since the structure and function of a protein are intrinsically interrelated, their comprehension is indispensable for drug design.

\subsection{Neurodegenerative Disorders with Increased S100ß Proteins Concentrations}

\subsubsection{Ischemic Stroke}

Ischemic Stroke (IS) is the leading cause of disability and death associated with old age. Health statistics revealed that with over 15 million cases of strokes recorded annually worldwide, methods to effectively diagnose and monitor therapy are needed [19]. The use of blood biomarkers is one of the methods that hold great potential in predicting the risk of stroke, diagnosing stroke as well as in monitoring treatment. Studies also reveal that among the two types of stroke (Ischemic and Haemorrhagic stroke), 87\% of diagnosed stroke cases are of Ischemic nature [1, 2]. IS occurs when brain cells die due to inadequate blood flow as a result of blockage of blood vessels leading to the brain [20]. At the onset of this neural disorder, S100 $\beta$ proteins are released continuously from the glial and Schwann cells into the blood and Cerebrospinal Fluid (CSF). This is due to astrocytic activation caused by deprivation of oxygen and nutrients [7]. Thus, the concentration of S100 $\beta$ proteins increases significantly at the onset of IS and correlates with infarct volume, stroke severity and functional outcome [8]. Hence, clinically, increased concentrations of S100 $\beta$ proteins in the blood and CSF serve as a useful neuro-biomarker in the diagnosis and long-term prediction of clinical outcomes pertaining to IS. The stressful physiochemical conditions in brain Ischemia results in protein misfolding and aggregation of abnormal proteins [21]. Due to the fact that the native three-dimensional conformation accounts for proper cellular function of a protein; any alteration in this tertiary structure either leads to a gain of other toxic functions or loss of key functions (e.g. the loss of motor functions which is prevalent in stroke patients). Hence, conformational changes due to unfavourable cellular conditions such as ion, $\mathrm{pH}$, temperature and ligands are important in the progression of protein misfolding pathologies as well as altering of biological activity.

\subsubsection{Alzheimer's Diseases}

Alzheimer's Disease (AD) is a neuropathological ailment which is characterized by a gradual increase in dementia. This kind of dementia impairs memory, thinking and behaviour. Symptoms usually progress slowly and worsen with time, becoming profound enough to inhibit the performance of daily tasks [22]. The characteristic neuro-pathological markers of AD are the formation of amyloid plaques and tangling of the neuro-fibrils. Patients suffering from AD experience a significant increase of $\mathrm{S} 100 \beta$ protein levels due to conformational changes as well as a seeming interplay 
between $\beta$-amyloids and expression of $\mathrm{S} 100 \beta$ protein. The $\beta$-amyloid stimulates the synthesis of both S100 $\beta$ mRNA and $\mathrm{S} 100 \beta$ protein in astrocyte cultures. Extracellular S100 $\beta$ might contribute to inflammations in the brain regions by astrocytes and microglial neurons activations. The inflammation affects the expression of S100 $\beta$ proteins, making it pathologically relevant in the degeneration of the Central Nervous System (CNS) in AD [13].

\subsubsection{Myocardial Infarction}

Myocardial Infarction (MI), usually known as heart attack occurs when there is a decreased perfusion to the heart tissues as a result of blockage of the left coronary artery. This results in an increased myocardial metabolic demand causing a decreased supply of nutrients and oxygen to the myocardial cells via the coronary circulation [14]. S100 $\beta$ is a well-known protein marker of brain damage. At the onset of MI, there is an increased concentration of S100 $\beta$ protein in the serum. This shows that, a careful assessment of the function and the structural alterations of these proteins in heart attack progression might contribute to a better understanding of the regulatory and counter regulatory mechanisms underlying the progressive decline in cardiac function in patients with myocardial infarction [15].

\subsection{Computational Modelling via Molecular Dynamics (MD) Simulations}

Computational modelling is basically the use of computational techniques to simulate and study the behaviour of complex systems using mathematics, physics, informatics, control theories and computer science. This platform uses various methods to desegregate tentative and scientific data into models used to demonstrate biomedical phenomena and exploit system responses, predictions and develop hypothesis [23]. From the above stems molecular dynamics simulation that simulates the trajectory of a system of particles. This is prominent for the generations of nonequilibrium ensembles as well as dynamic events analysis. Molecular dynamics simulation is based on Newton's equation of motion represented as:

$$
\left(\frac{d^{2} r_{i}}{d t^{2}}=\frac{F_{i}}{m_{i}}\right)
$$

where, $F_{i}$ is the force on any atom, $r_{i}$ is the positions of atoms in the system and $m_{i}$ is the atom mass.

This equation of molecular dynamic simulations is prominent in classical mechanics and from it stems varied algorithms to simulate trajectories of a system of particles [24]. Thus, the movement of the atoms is simulated by numerically solving the Newton's equations of motion based on the summation of the forces between non-bonded and bonded atom interactions as well as restrains and/or external forces. This allows the determination of the potential and kinetic energies of the atoms as well as its pressure tensor [25]. These simulations help in determining the structural alterations of complex systems and are employed in studying the conformational dynamics of S100 $\beta$ protein at varying physiochemical parameters to unravel new knowledge in supporting clinical decisions.

\section{MATERIALS AND METHOD}

The X-ray crystal structure of the S100 $\beta$ protein (PDB ID: 5D7F) with a resolution of $1.3 \AA$ was acquired from Protein Data Bank (PDB) [26]. PDB files contain standard atomistic coordinates, experimental method, resolution and secondary structure of a protein [26]. Chain A of the 5D7F structure was utilized in the computational modeling since it binds to more glycerol ligands as opposed to the chain B from the solved structure. The equilibrium structure of S100 $\beta$ was obtained by a long-time-scale molecular dynamics (MD) simulation using GROningen MAchine for Chemical Simulations (GROMACS) 5.0.3 [27]. Chiron [28] and YASARA [29] servers were used to predict the steric clashes, void volume and optimization of the protein. Single Point Charge (SPC) water model was used to solvate the protein without considering hydration shells. Furthermore, equivalent number of $\mathrm{Na}^{+}$ions were added to make the simulation system electrically neutral to determine the molecular conformation of the protein. Energy minimization was applied to reduce and stabilize the large forces and structural distortions due to the number of hydrogens added as well as the broken hydrogen bond networks. The pressure, temperature and volume equilibration of the system was performed using the total number of Particles-Pressure-Temperature (NPT) and Particles-Volume-Temperature (NVT) ensembles for $1000 \mathrm{~ns}$, and the coordinates were saved at $1 \mathrm{ps}$ frame intervals.

All the simulations were conducted utilizing the Optimized Potential for Liquid Simulations All Atom (OPLS AA) force fields and Assisted Model Building with Energy Refinement (AMBER) force fields [30, 31]. GROMACS 5.0.3, a platform used to perform molecular dynamic simulations and energy minimization utilities such as sasa, hbonds, rms 
and rmsf were used to analyse the simulation data [27]. The same simulation protocol was used to assess the conformational dynamics of the protein regarding cofactor-bound $\mathrm{S} 100 \beta$ protein as well as temperature variations. The pressure equilibration algorithm employed was the Berendsen coupling thermostat scheme. The long range electrostatic interactions of the protein were calculated using the Linear Constraint Solver (LINCS) algorithm defined in GROMACS with a cut-off length of $1 \mathrm{~A}^{\circ}$ for the Van der Waals interactions. The trajectories were saved every $100 \mathrm{ps}$ frame and the total NPT and MD run simulation time was 10000 ps for each case of temperature simulated. The resulting structures from the simulations were uploaded to Protein Data Bank Summary (PDBsum) Server for secondary structure contents analysis [32]. Ambertools17 [30] was used to protonate the amino acid residues of the protein to mimic the various $\mathrm{pH}$ values using the constant $\mathrm{pH}$ molecular dynamics (CpHMD) techniques. Metal Ion Binding (MIB) server was also utilized to assess the binding sites of the protein-cofactor complex [33]. Open Babel software [34] was also used to convert PQR file to PDB file format. Xmgrace plotting tool was used to plot the data obtained from the MD simulations. Statistical analysis was performed using IBM SPSS Statistics version 20 [35]. Statistical computations were undertaken using 95\% confident intervals to determine the significant differences among the results obtained from the simulations. The error bars in the graphs also depicts statistically significant differences among the quantitative results obtained from the simulations.

\section{RESULTS AND DISCUSSION}

\section{1. pH-Induced Conformational Changes}

A statistical measure of the root-mean-square deviation (RMSD) between corresponding atoms in protein structures can aid in obtaining the protein conformational changes at different physiological parameters [36]. The structure of $\mathrm{S} 100 \beta$ was monitored as a function of $\mathrm{pH}$ and the RMSD values depicts the average distance between the backbone atoms (Fig. 2). For the different pH 5.0, 7.4, and 9.0, considerable conformational changes were observed during the initial few picoseconds of the RMSD values $(0.8824,0.8431$, and $0.8288 \mathrm{~mm})$, respectively. The size of the backbone fluctuation is maximum at $\mathrm{pH} \sim 5.0$ and decreases with basic $\mathrm{pH}$ values. Statistically, there was no significant difference in the RMSD between the physiological and basic $\mathrm{pH}$ values.

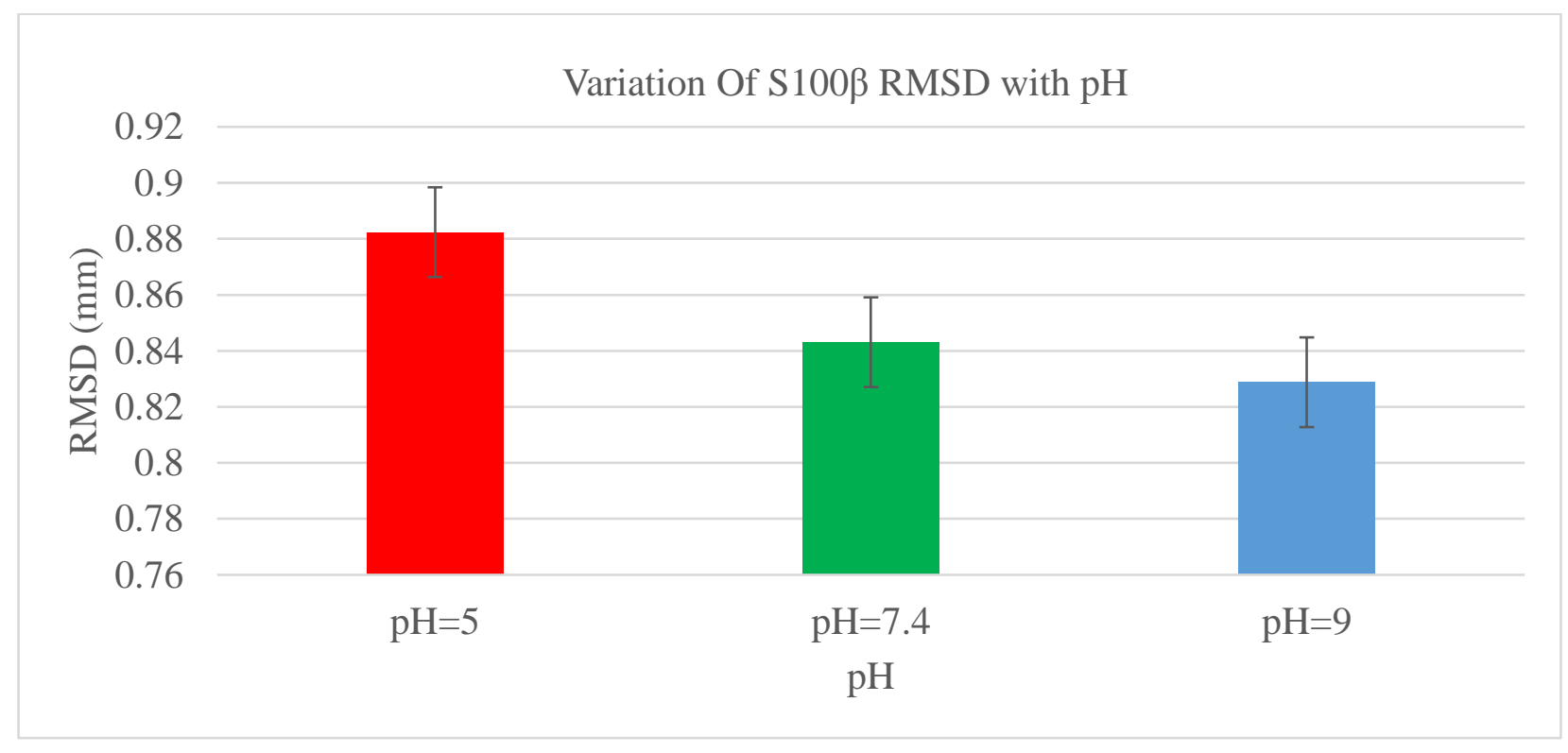

Fig. (2). Root-mean-square deviation (RMSD) versus time graph. The graph determines the backbone fluctuations of S100 $\beta$ protein at varied $\mathrm{pH}$ values.

\subsection{Temperature-Induced Conformational Changes}

In order to understand the behaviour of $\mathrm{S} 100 \beta$ protein at varying temperatures (i.e. 100 to $400 \mathrm{~K}$ ), MD simulations using the Berendsen coupling scheme in GROMACS were conducted. Graphs of RMSD, the Root-Mean-Square Fluctuation (RMSF), hydrogen bonds as well as solvent accessible surface area (SASA) versus time at the various temperatures $(100 \mathrm{~K}, 200 \mathrm{~K}, 300 \mathrm{~K}, 310 \mathrm{~K}$ and $400 \mathrm{~K})$ are displayed in Fig. (3). As shown in Fig. (3a), the RMSD graph 
for each temperature changes significantly with $400 \mathrm{~K}$ having the highest deviation. Simulation at $400 \mathrm{~K}$ was basically performed to explore how higher temperatures could compromise the structural alterations of a protein. The results indicate a positive correlation between temperature and conformational stability. Further comparison of the crystallization $(200 \mathrm{~K})$ and physiological $(310 \mathrm{~K})$ temperatures showed a relatively low deviation in the former, depicting small deviations of the residues from the backbone as a function of time. In order to evaluate the individual residue fluctuations of the protein at the different temperatures, RMSFs were generated from trajectory analysis obtained by the molecular dynamic simulation and are shown in Fig. (3b). The RMSF plot at the different temperatures showed distinct fluctuations with $400 \mathrm{~K}$ having the highest fluctuation at the protein termini.

A

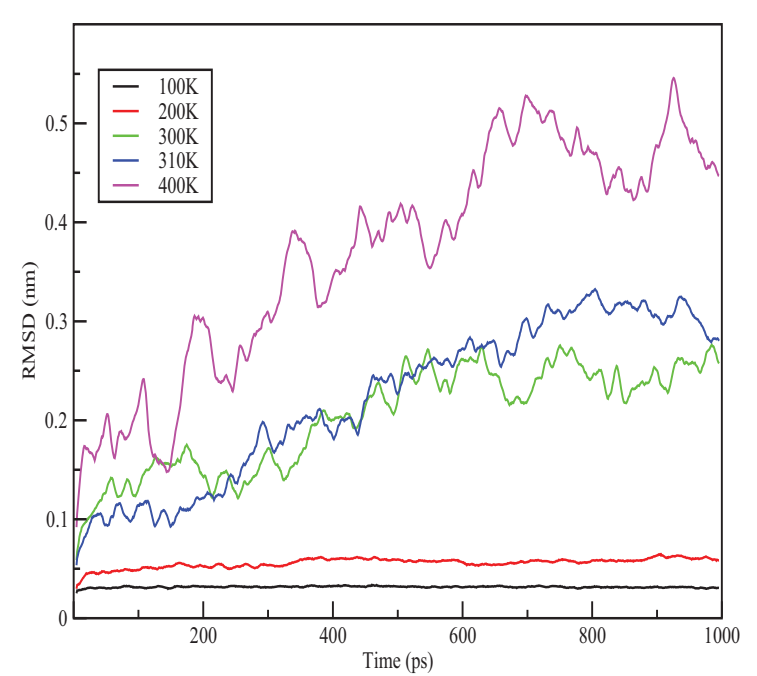

C

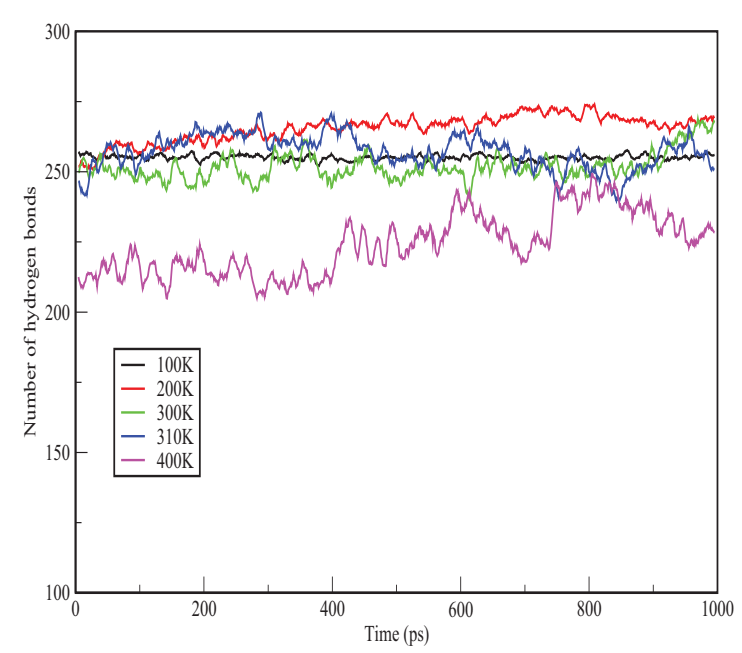

B

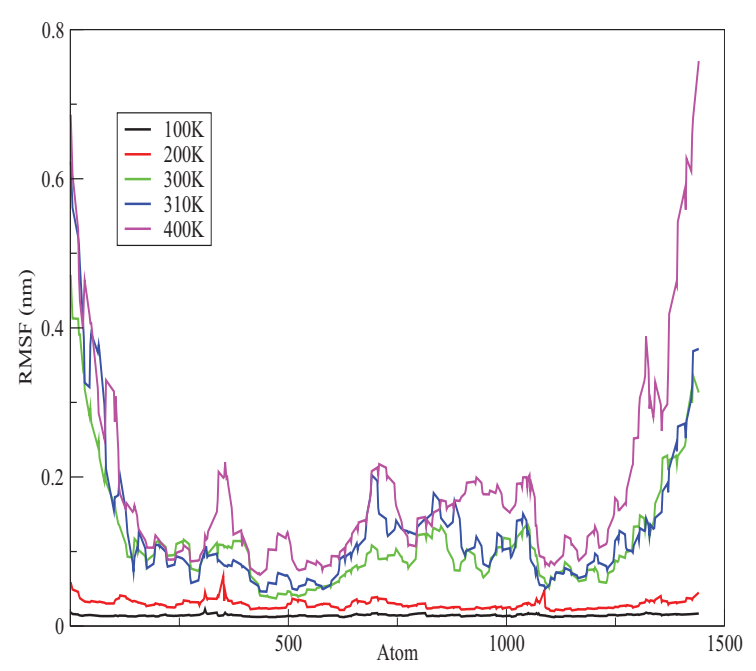

$\mathrm{D}$

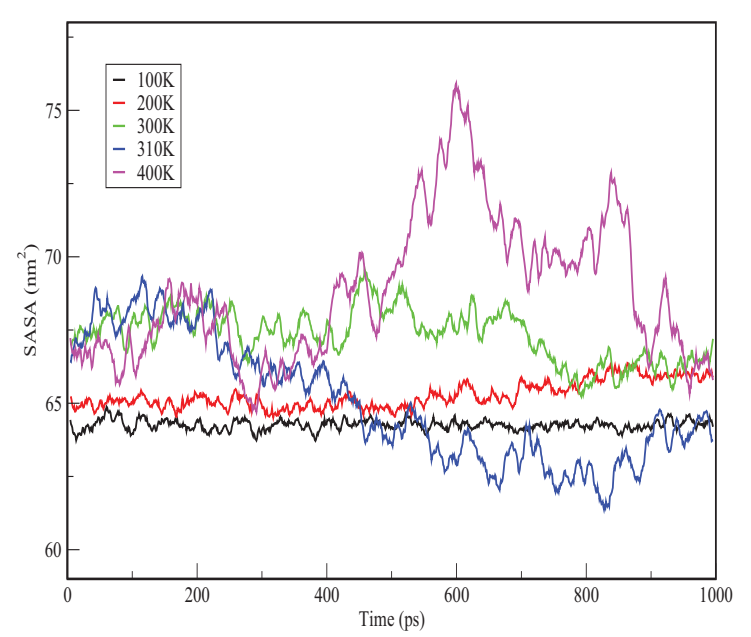

Fig. (3). Temperature variations analysis. (A) Root-mean-square deviation (RMSD); (B) root-mean- square fluctuation (RMSF); (C) hydrogen bond; and (D) Solvent Accessible Surface Area (SASA) versus time at varied temperatures.

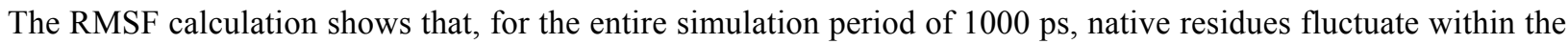
range of $\sim 0.05-0.6 \mathrm{~nm}$. It can therefore be predicted that higher temperatures confer much fluctuations and flexibility in the $\mathrm{S} 100 \beta$ structure and that the termini are the most flexible portions of the protein. Furthermore, structural changes in the flexibility of chain A of S100 $\beta$ was further examined by the number of hydrogen bonds formed during the simulation experiment. Hydrogen bonds are important in predicting the fold in a protein. Variations in the number of 
hydrogen bonds and bond length affect the stability of a protein [37]. As indicated in Fig. (3c), the hydrogen bond graph showed significant variations at different temperatures (i.e. $100-400 \mathrm{~K}$ ) with $400 \mathrm{~K}$ having the lowest number of hydrogen bonds. This could be due to the formation of more unstructured regions of S100 $\beta$ at higher temperatures. It can be suggested that higher temperatures result in the destruction of the hydrogen bonds holding the secondary and tertiary structures together. The SASA graph shown in Fig. (3d) depicts significant variations at different temperatures (i.e. $100 \mathrm{~K}-400 \mathrm{~K}$ ) with $400 \mathrm{~K}$ having the highest area of approximately $76 \mathrm{~nm}^{2}$. This portrays that more hydrophobic residues get exposed at high temperatures which indicates denaturation marked by an increase in the exposed surface area as water solvates the unfolding proteins.

A

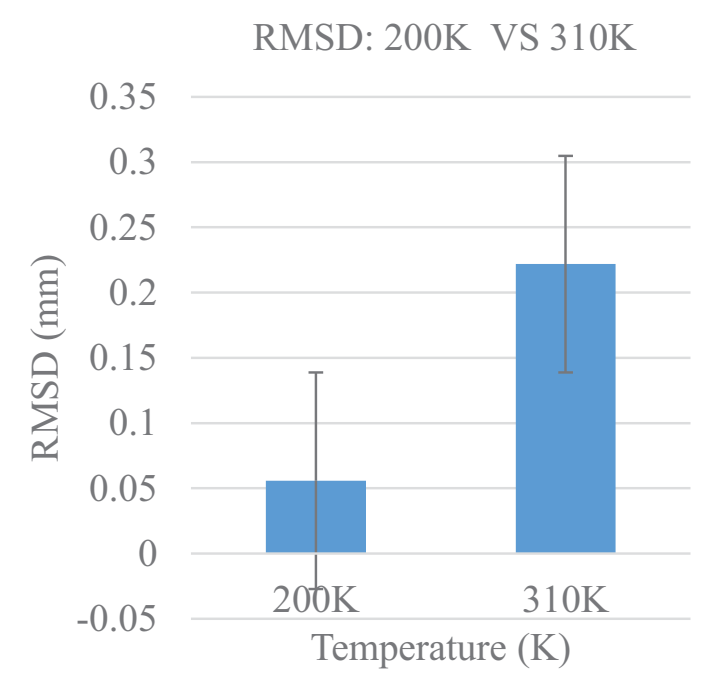

C

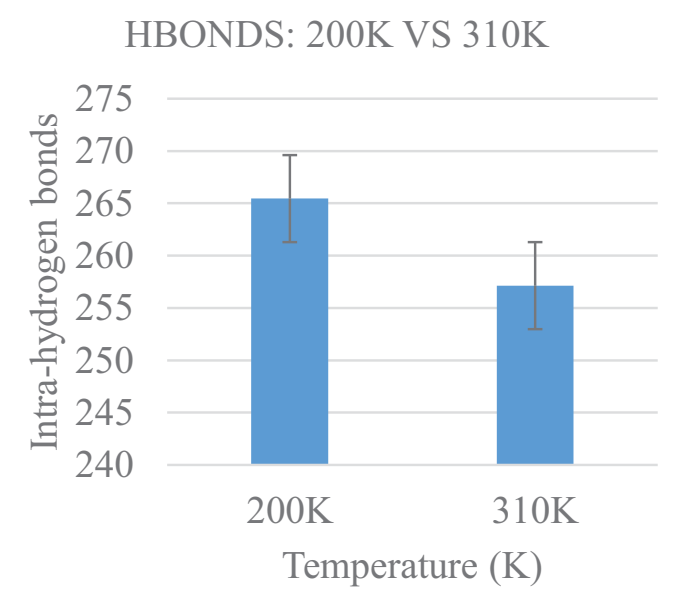

$\mathrm{B}$

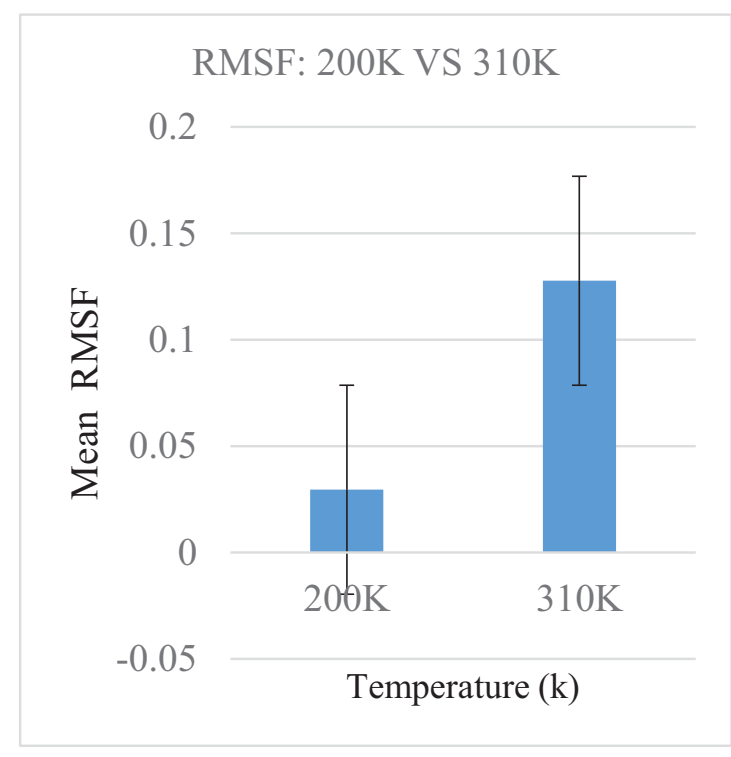

D

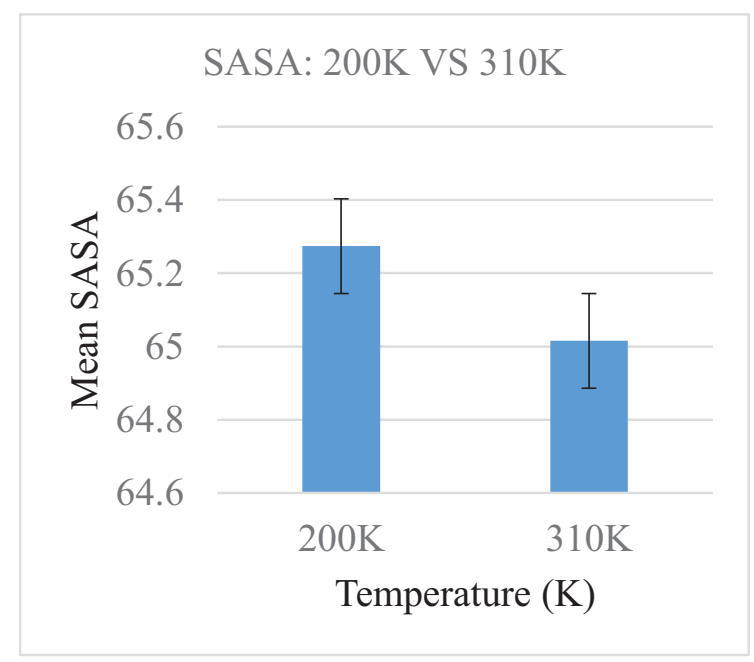

Fig. (4). Physiological and crystallization temperature analysis. (A) Root-mean-square deviation (RMSD); (B) root-mean-square fluctuation (RMSF); (C) hydrogen bond; and (D) Solvent Accessible Surface Area (SASA) of S100ß protein bar graphs compared at $200 \mathrm{~K}$ and $310 \mathrm{~K}$.

Bar graphs of RMSD, RMSF, Hydrogen bond as well as Solvent Accessible Surface Area (SASA) versus the time of the crystallization $(200 \mathrm{~K})$ and physiological temperatures $(310 \mathrm{~K})$ are compared and shown in Fig. (4). The mean RMSD for the crystallization $(200 \mathrm{~K})$ and physiological $(310 \mathrm{~K})$ temperatures are compared in Fig. (4a). The mean RMSF values for the crystallization $(200 \mathrm{~K})$ and physiological $(310 \mathrm{~K})$ temperatures are also compared in Fig. (4b). The 
RMSF graphs show significant variations between the crystallization and physiological temperatures. This is an indication of distinct fluctuations within the protein at the higher temperature. Also, in Fig. (4c), it can be observed that the individual amino acids are held by a relatively larger number of hydrogen bond networks at $200 \mathrm{~K}$ compared to the number of hydrogen bonds at $310 \mathrm{~K}$. Fig. (4d) shows the solvent accessible surface area of the protein at $200 \mathrm{~K}$ and $310 \mathrm{~K}$. At $310 \mathrm{~K}$, the protein becomes less compact and accordingly more regions which were initially buried at the crystallization temperature are exposed to interact with the solvent.

\subsection{Temperature-Induced Secondary Structure Analysis}

The secondary structure of a protein is the geometric structure caused by intermolecular and intramolecular hydrogen bonding of the amide groups [38]. Fig. (7a) shows the comparison between the secondary structure of the protein at $200 \mathrm{~K}$ and $310 \mathrm{~K}$. Uniform formations of alpha helices at $200 \mathrm{~K}$ were compared to non-uniform formation of alpha helices at $310 \mathrm{~K}$. The alpha helices of the protein at $200 \mathrm{~K}$ were higher in number and more confined than that at $310 \mathrm{~K}$. This is due to the significant reduction and breakage of these alpha helices as a result of the destruction of the intramolecular hydrogen bonds holding the structure together. This illustrates changes in the conformational stability due to the varied metal-ion binding sites of the protein. Hence temperature appears to affect the conformational changes of $\mathrm{S} 100 \beta$ proteins.

\subsection{Metal Ions Induced Conformational Changes}

The conformational changes of the $\mathrm{S} 100 \beta$ protein was investigated at $\mathrm{pH} \sim 7.4$ in the presence of $\mathrm{Ca}^{2+}$ since the metal ion is preferred for physiological functioning of $\mathrm{S} 100 \beta$ protein. The outcome of the binding was compared with other metal ions such as $\mathrm{Zn}^{2+}$ and $\mathrm{Mg}^{2+}$ The metal ions were selected for the prediction due to the fact that they are rich in the synaptic regions of the brain where $\mathrm{S} 100 \beta$ protein is found. In Table $\mathbf{1}$, unlike $\mathrm{Zn}^{2+}$, it is evident that $\mathrm{Ca}^{2+}$ and $\mathrm{Mg}^{2+}$ bind to the same protein residues. The residues that are in contact with $\mathrm{Ca}^{2+}$ and $\mathrm{Mg}^{2+}$ include $62 \mathrm{D}, 64 \mathrm{D}, 66 \mathrm{D}, 68 \mathrm{E}$ and $73 \mathrm{E}$, however, the binding affinity score for $\mathrm{Ca}^{2+}$ is higher. The RMSD was calculated for hydrogen bond interactions in the $\mathrm{S} 100 \beta$ protein after one least square fit for the different protein-metal ion trajectories. For the different metal ions, considerable conformational changes were observed during the early few picoseconds with RMSD value of $0.1 \mathrm{~nm}$ as shown in Fig. (5a). The RMSD graph for each of the protein-metal ion complex varied significantly with $\mathrm{Ca}^{2+}-\mathrm{S} 100 \beta$ complex having the highest deviation followed by $\mathrm{Mg}^{2+}$ and $\mathrm{Zn}^{2+}$. Even though, $\mathrm{Mg}^{2+}$ has more residue contacts compared to $\mathrm{Zn}^{2+}$, there is no significant deviation in terms of the RMSD between the two metal ions. Accordingly, it can be deduced that $\mathrm{Mg}^{2+}$ and $\mathrm{Zn}^{2+}$ ions confer conformational dynamics to the $\mathrm{S} 100 \beta$ which could compromise its cellular functions.

Table 1. Metal Ion Binding (MIB) Server [33] results showing the different binding affinities and the different interacting residues per cofactor-bound $\mathrm{S} 100 \beta$ protein with the cofactors represented as spherical balls.

\begin{tabular}{|c|c|c|c|}
\hline Cofactor-Bond S100 $\beta$ & Binding Residues & Binding Scores & 3D Model of the Best Binding Mode \\
\hline \multirow{2}{*}{$\mathrm{Ca}^{2+}-\mathrm{S} 100 \beta$} & $62 \mathrm{D}, 64 \mathrm{D}, 66 \mathrm{D}, 68 \mathrm{E}, 73 \mathrm{E}$ & 2.891 & \\
\hline & $62 \mathrm{D}, 64 \mathrm{D}, 65 \mathrm{G}, 66 \mathrm{D}, 68 \mathrm{E}, 69 \mathrm{C}, 73 \mathrm{E}$ & 2.766 & \\
\hline \multirow{2}{*}{$\mathrm{Mg}^{2+}-\mathrm{S} 100 \beta$} & $62 \mathrm{D}, 64 \mathrm{D}, 66 \mathrm{D}, 68 \mathrm{E}$ & 2.031 & \\
\hline & $62 \mathrm{D}, 64 \mathrm{D}, 66 \mathrm{D}, 68 \mathrm{E}, 73 \mathrm{E}$ & 1.944 & \\
\hline
\end{tabular}


(Table 1) contd.....

\begin{tabular}{|c|c|c|c|}
\hline Cofactor-Bond S100ß & Binding Residues & Binding Scores & 3D Model of the Best Binding Mode \\
\hline \multirow{3}{*}{$\mathrm{Zn}^{2+}-\mathrm{S} 100 \beta$} & $86 \mathrm{H}, 87 \mathrm{E}$ & 1.538 & \\
\hline & & & \\
\hline & $55 \mathrm{D}, 59 \mathrm{E}$ & 1.480 & \\
\hline
\end{tabular}

A

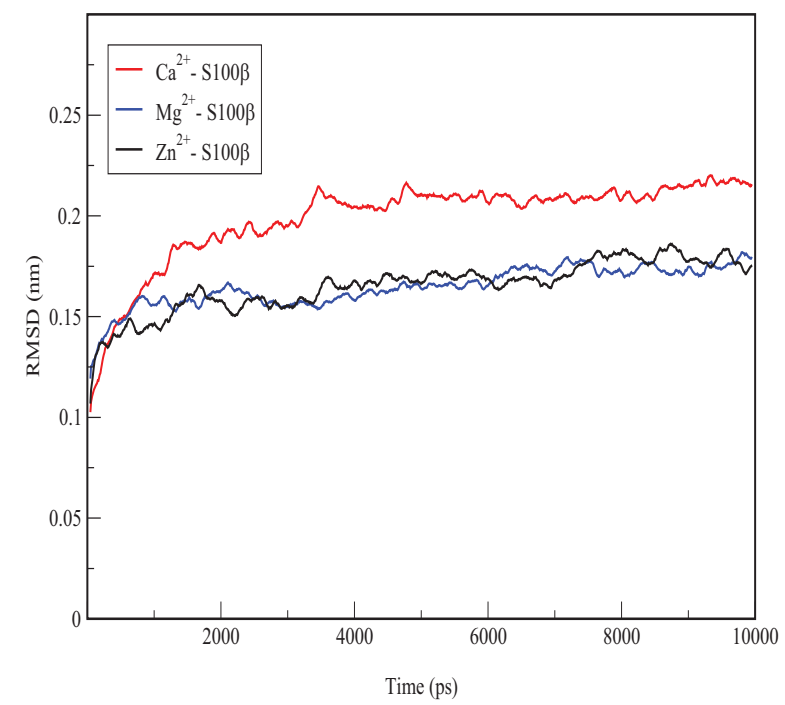

C

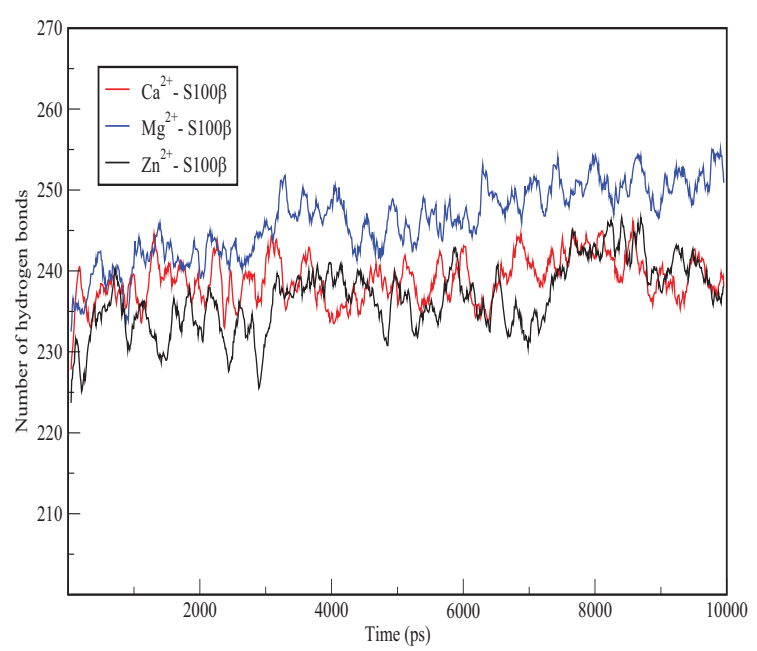

B

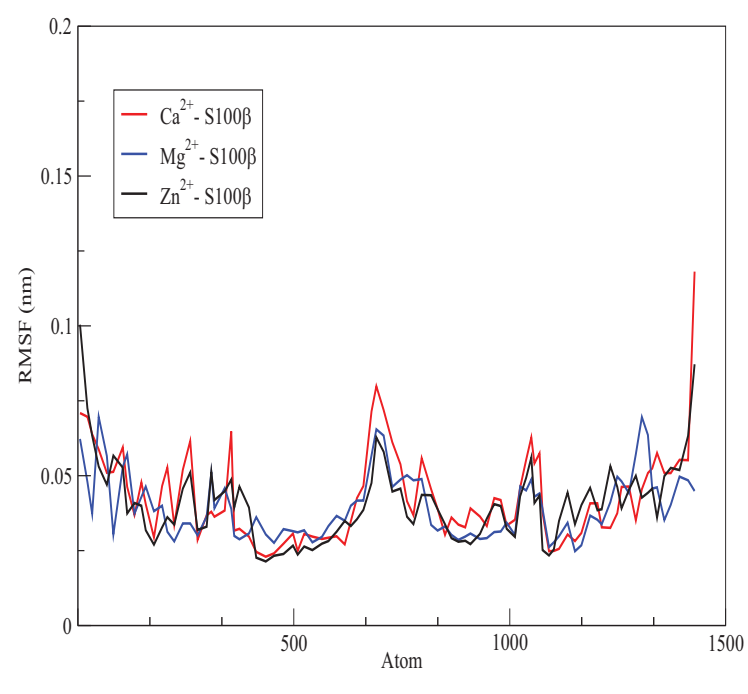

D

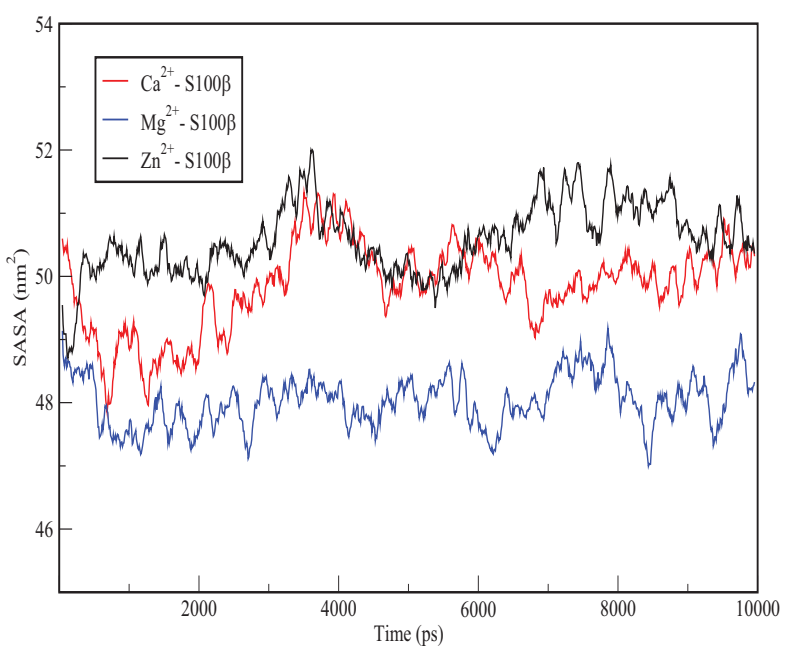

Fig. (5). Cofactor-bound S100ß analysis. (A) Graphs of root-mean-square deviation (RMSD); (B) Root- Mean-Square Fluctuation (RMSF); (C) hydrogen bond; and (D) Solvent Accessible Surface Area (SASA) for different protein-cofactors (zinc, calcium and magnesium) complexes.

In order to evaluate the individual residue fluctuations of the protein-cofactor complex, RMSF graphs were 
generated from trajectory analysis obtained from MD simulations and the results are displayed in Fig. (5b). The RMSF calculations show that in the whole simulation period of $1000 \mathrm{ps}$, residues showed fluctuation values within $0.25-0.1$ $\mathrm{nm}$. Stable regions of a protein depict lesser fluctuations as compared with flexible regions. After $10 \mathrm{~ns}$ of simulation using GROMACS with different metal ions, it can be deduced that $\mathrm{Zn}^{2+}$ and $\mathrm{Mg}^{2+}-\mathrm{S} 100 \beta$ complexes show higher stability as compared with $\mathrm{Ca}^{2+}-\mathrm{S} 100 \beta$ complex. Bonds made in $\mathrm{Zn}^{2+}$ and $\mathrm{Mg}^{2+}-\mathrm{S} 100 \beta$ complexes binding sites stabilize the protein-metal ion complex and thereby reduce its flexibility depicting a unique conformational change. This flexibility appears to be accounted for by motions in the loops and hairpins around the active site of the protein.

Structural changes in the flexibility of the $S 100 \beta$ protein were further analysed by determining the number of hydrogen bonds formed and the results are shown in Fig. (5c). The mean number of hydrogen bonds and distribution at varied protein-cofactor complexes were analysed. The average number of hydrogen bonds per frame is higher in $\mathrm{Mg}^{2+}-$ $\mathrm{S} 100 \beta$ complex as compared with $\mathrm{Ca}^{2+}$ and $\mathrm{Zn}^{2+}-\mathrm{S} 100 \beta$ complexes. This is probably due to the high electronegativity of magnesium which favours the attraction of hydrogen atoms in the formation of hydrogen bonds. The average number of hydrogen bonds ranges from 225 to 242 at different protein-cofactor complexes. This plays relevant roles in the maintenance of the secondary and tertiary structure of a protein. Moreover, hydrogen bonds are important in predicting the specific molecular interactions in biological recognition processes of a protein. Changes in the hydrogen bond pairs within $0.35 \mathrm{~nm}$ distance and angle, may affect the conformational stability of a protein [37]. The hydrogen bond graph exhibited significant variations at different protein-cofactor complex, with $\mathrm{Zn}^{2+}-\mathrm{S} 100 \beta$ complex having the lowest number of hydrogen bonds depicting protein instability as shown in Fig. (5c). This is possibly due to the formation of more unstructured regions of $\mathrm{S} 100 \beta$ at different protein-cofactor complexes.

The Solvent Accessible Surface Area (SASA) is a measure of the accessibility of a solvent to the hydrophobic core of a protein [39]. Variations in the solvent accessible surface area indicates the change in the exposed amino acid residues and could affect the secondary and tertiary structure of proteins. The SASA graph (Fig. 5d) showed significant variations with $\mathrm{Ca}^{2+}-\mathrm{S} 100 \beta$ complex and $\mathrm{Zn}^{2+}-\mathrm{S} 100 \beta$ complex as having the highest exposed surface area of approximately $50.2 \mathrm{~nm}^{2}$. The average SASA values revealed significant difference between calcium and magnesium. This could be as a result of the burial of the hydrophobic residues into the core, signifying a conformational change in tertiary structure of the $\mathrm{S} 100 \beta$ protein.

From Fig. (6a), the binding of a cofactor to the native $\mathrm{S} 100 \beta$ at $310 \mathrm{~K}$ causes a conformational change which is manifested as a disappearance of an appreciable number of hydrogen bonds. This further confirms that $\mathrm{S} 100 \beta$ is activated by metal-ion binding for physiological functioning. It can also be observed that $\mathrm{Mg}^{2+}$-bound $\mathrm{S} 100 \beta$ has more hydrogen bond networks present than that of $\mathrm{Ca}^{2+}$ and $\mathrm{Zn}^{2+}$-bound states.

In Fig. (6b), the apo-S100 $\beta$ has more residues interacting with the solvent than the cofactor- bound S100 $\beta$ protein at $37^{\circ} \mathrm{C}(310 \mathrm{~K})$. The cofactor-bound protein has more regions buried in the hydrophobic core and hence less surface area accessible to the solvent. This shift in the unfolding of buried residues from the hydrophobic core signifies conformational alterations triggered by cofactors at the physiological temperature. Moreover, Fig. (6c) shows the changes in the secondary structure of the alpha-helices as a function of temperature. From the same bar graph, the $310 \mathrm{~K}$ had lower percentage of alpha helical structures as compared to $200 \mathrm{~K}$. As helical content of a protein determines its stability, the more the alpha-helix present in a protein structure, the more stable it is [4]. Accordingly, the protein misfolds as temperature increases thereby causing a conformational change in the S100 $\beta$ protein. Also, Fig. (6d) indicates the changes in the secondary structure alpha-helices with different cofactors of the protein. From the bar graph (Fig. 6d), $\mathrm{Zn}^{2+}$-S100 $\beta$ also had the lowest percentage of helical content. Hence, the different cofactors-bound S100 $\beta$ protein affects the conformational changes of $\mathrm{S} 100 \beta$ proteins.

\subsection{Secondary Structure Analysis of Protein-Cofactor Complexes}

Fig. (7b) shows the number of residues and the corresponding secondary structures in each frame of the MD simulations for different cofactors bound to $\mathrm{S} 100 \beta$. The secondary structure analyses were conducted to elucidate the regions that are essential in the structural changes of a protein caused by intermolecular and intramolecular hydrogen bonding of the amide group [22]. Highly fluctuated residues show a higher inclination for the formation of unstructured protein regions than regular $\alpha$-helical and $\beta$-strands secondary structural elements as depicted in the RMSF graph at different protein-cofactor complexes. Additionally, it shows the comparison between the secondary structures of the respective protein-cofactor complexes. Uniform formation of alpha helices at residue 3 to 16 for $\mathrm{Ca}^{2+}$-bound protein was identified and compared to a non-uniform formation of alpha helices at residue 15 to 19 for $\mathrm{Zn}^{2+}$-bound $\mathrm{S} 100 \beta$ protein 
secondary structure. The alpha helices of the $\mathrm{Mg}^{2+}-\mathrm{S} 100 \beta$ was higher in number and confined relative to $\mathrm{Zn}^{2+}-\mathrm{S} 100 \beta$ with the characteristic appearance of two beta hairpins.

A

B

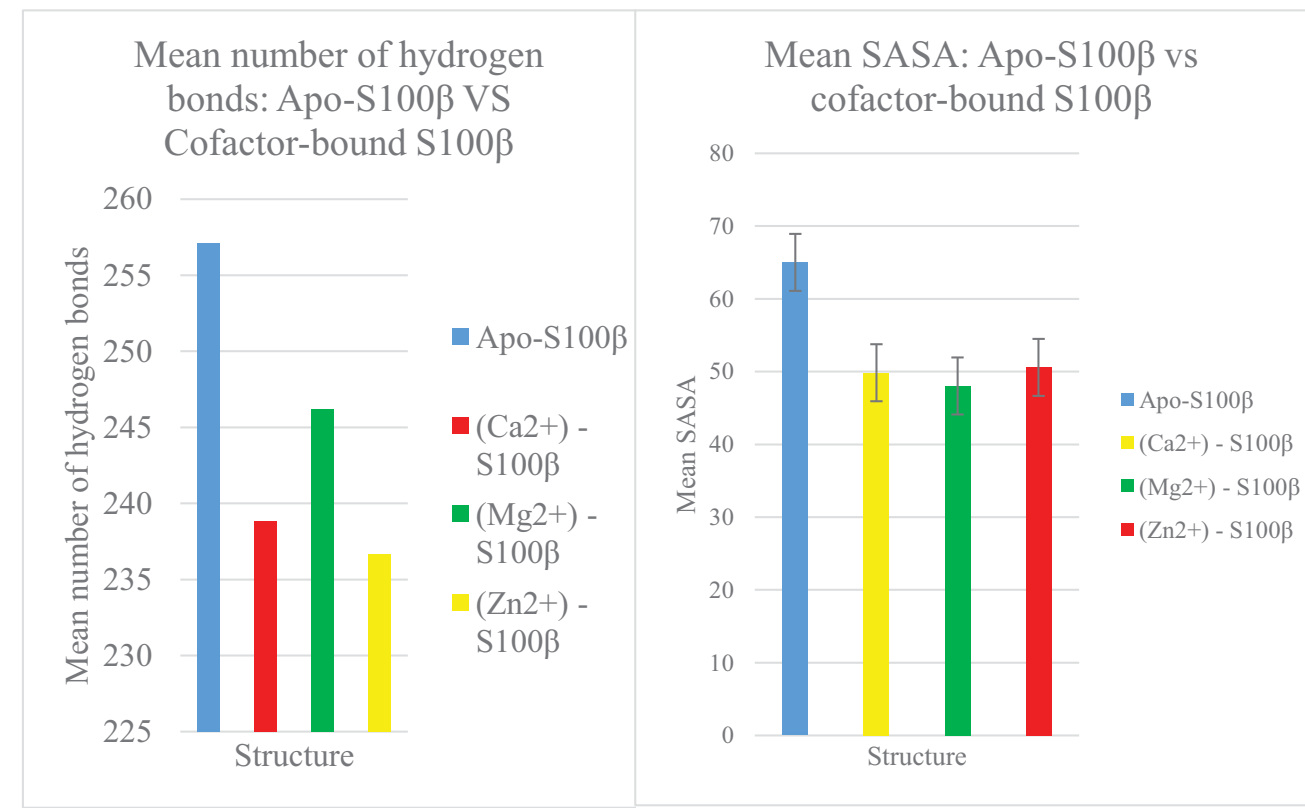

C

$\mathrm{D}$

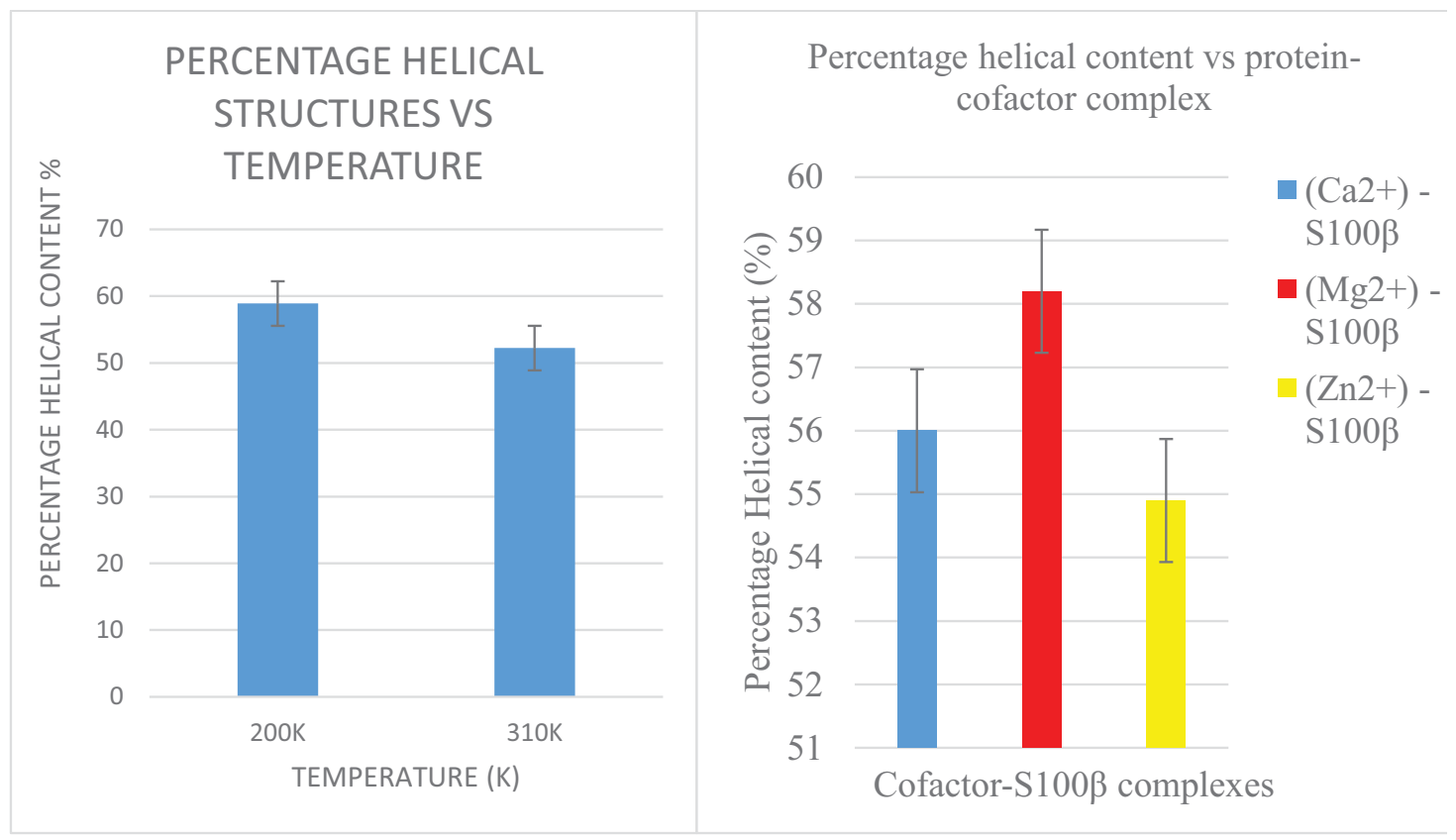

Fig. (6). Metal ions induced conformational change studies. (A) Number of hydrogen bonds of apo-protein versus protein-cofactor complex; (B) comparison of means of Solvent Accessible Surface area of protein-cofactor complexes with apo-Protein; (C) secondary structure alpha- helix percentage at 200K and 310K; and (D) secondary structure alpha-helix percentage at varied proteincofactor complex. 
A

\begin{tabular}{|c|c|}
\hline TEMPERATURE (K) & SECONDARY STRUCTURE \\
\hline \multirow[t]{2}{*}{200} & \\
\hline & \begin{tabular}{|llllllllllllllllll} 
i & 10 & 15 & 20 & 25 & 30 & 35 & 40 & 45 & 50 & 55 & 60 & 65 & 70 & 75 & 80 & 85 & 90
\end{tabular} \\
\hline \multirow[t]{3}{*}{310} & 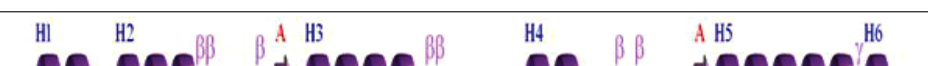 \\
\hline & MSELEKAWAL IDVFHOYSGREGDKHKLKKSELKELINNELSHFLEEIKEQEVWDKUETLDNDGDGECDFOEAMAFVANTTACHEFFEH \\
\hline & 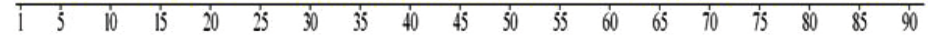 \\
\hline
\end{tabular}

B

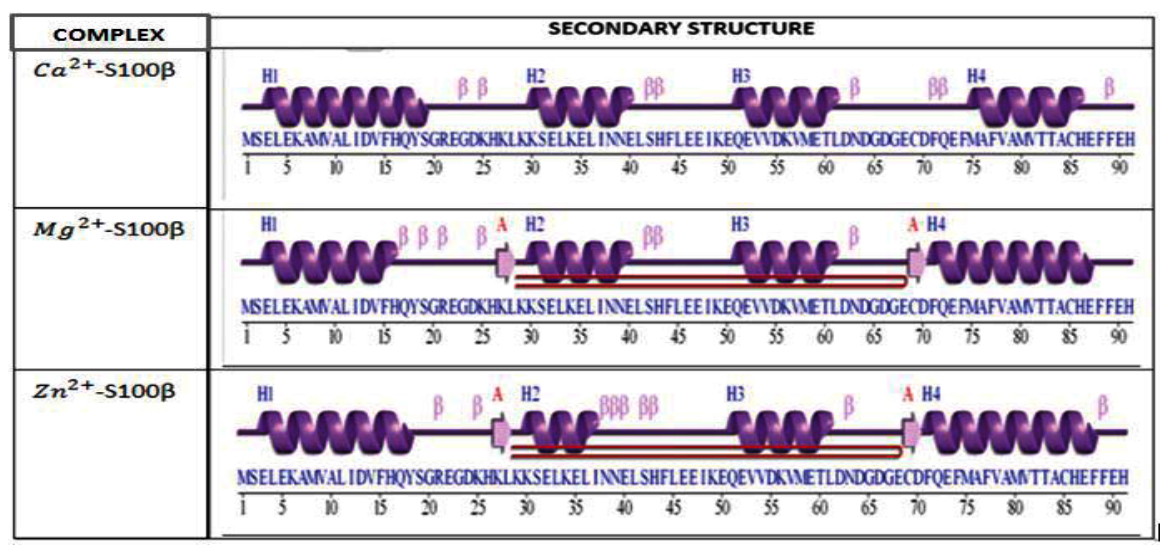

Fig. (7). Secondary structure analysis. (A) Changes in the secondary structure at 200K and 310K; and (B) changes in the secondary structure at varied protein-cofactor complexes.

\section{SUMMARY OF FINDINGS AND ITS IMPLICATIONS}

As part of the model verification, the different binding domains of the cofactors identified were closely related to experimental binding positions of typical EF-hand (EF-2: D61-E72) [12]. The molecular dynamics simulations of the different protein-cofactor complex appear to have minor structural changes when $\mathrm{Ca}^{2+}$ is bound to the pseudo-EF-hand as opposed to the typical EF-hand. Different S100 $\beta$ structural alterations which could be biologically relevant were identified as a result of the weak binding affinity of the cofactors. The low binding affinity of the cofactors appear to trigger the higher concentrations of $\mathrm{S} 100 \beta$ proteins in cells without depleting the cofactors levels [40]. The molecular dynamics simulations also corroborate that $\mathrm{Ca}^{2+}, \mathrm{Mg}^{2+}$ and $\mathrm{Zn}^{2+} \mathrm{S} 100 \beta$ complexes are relevant secondary messengers in all living cells, since these cofactors helps to maintain the integrity of ion signalling and transmission in a spatially coordinated manner.

Moreover, the different binding domains of the cofactors divulges the varied affinities of the divalent metal ions. This may also help in understanding oligomerization properties as well as posttranslational modification enhancement (relevant in drug resistance) in the characterization of $\mathrm{S} 100 \beta$ proteins. Also, $\mathrm{Ca}^{2+}$-bound $\mathrm{S} 100 \beta$ proteins appears not to only cause structural transitions and alterations but also results in a tighter dissemination of helices within the EF-2 binding motif relevant for target protein interactions. Additionally, acidic $\mathrm{pH}(\sim 5.0)$ appears to confer conformational instability to $\mathrm{S} 100 \beta$ proteins. Protein misfolds at higher temperatures by the disappearance of helical regions which are responsible for proper folding. It was observed that at $100 \mathrm{~K}$ and $400 \mathrm{~K}$, alpha helical content was $57.8 \%$ and $43.3 \%$, respectively. 


\section{CONCLUSION}

The study aimed to investigate the impact of physicochemical factors such as temperature, $\mathrm{pH}$ and selected cofactors on the conformation dynamics of $\mathrm{S} 100 \beta$ protein. There were significant changes that were observed in the conformation and folding patterns of $\mathrm{S} 100 \beta$ protein and how they relate to the type of bound co-factor $\left(\mathrm{Ca}^{2+}, \mathrm{Mg}^{2+}\right.$ and $\mathrm{Zn}^{2+}$ ). The backbone fluctuations of the $\mathrm{S} 100 \beta$ protein were shown to be higher in acidic medium. The two binding motifs of the protein were not affected appreciably by varying temperatures. The studies provide great potential for experimental and structural characterisation of the $S 100 \beta$ protein. Even though, these findings are primarily based on computational predictions; experimental validation could enrich existing efforts geared towards exploiting S100 $\beta$ as a potent diagnostic biomarker as well as the design of novel drugs.

\section{ETHICS APPROVAL AND CONSENT TO PARTICIPATE}

Not applicable.

\section{HUMAN AND ANIMAL RIGHTS}

No animals/humans were used for studies that are the basis of this research.

\section{CONSENT FOR PUBLICATION}

Not applicable.

\section{CONFLICT OF INTEREST}

The authors declare no conflict of interest, financial or otherwise.

\section{ACKNOWLEDGEMENTS}

We would like to acknowledge support from the West African Centre for Cell Biology of Infectious Pathogens (WACCBIP).

\section{REFERENCES}

[1] D.L. Nash, M.F. Bellolio, and L.G. Stead, "S100 as a marker of acute brain ischemia: a systematic review", Neurocrit. Care, vol. 8, no. 2, pp. 301-307, 2008. [http://dx.doi.org/10.1007/s12028-007-9019-x] [PMID: 17968519]

[2] A. Hermann, R. Donato, T.M. Weiger, and W.J. Chazin, "S100 calcium binding proteins and ion channels", Front. Pharmacol., vol. 3, no. APR, p. 67, 2012. [PMID: 22539925]

[3] I. Salama, P.S. Malone, F. Mihaimeed, and J.L. Jones, "A review of the S100 proteins in cancer", Eur. J. Surg. Oncol., vol. 34, no. 4, pp. 357-364, 2008. [http://dx.doi.org/10.1016/j.ejso.2007.04.009] [PMID: 17566693]

[4] B.J. Grant, A.A. Gorfe, and J.A. McCammon, "Large conformational changes in proteins: signaling and other functions", Curr. Opin. Struct. Biol., vol. 20, no. 2, pp. 142-147, 2010. [http://dx.doi.org/10.1016/j.sbi.2009.12.004] [PMID: 20060708]

[5] F. Secundo, "Conformational changes of enzymes upon immobilisation", Chem. Soc. Rev., vol. 42, no. 15, pp. 6250-6261, 2013. [http://dx.doi.org/10.1039/c3cs35495d] [PMID: 23482973]

[6] V. Bellotti, and M. Stoppini, "Protein misfolding diseases", Open Biol. J., pp. 228-234, 2009.

[7] R. Donato, B.R. Cannon, G. Sorci, F. Riuzzi, K. Hsu, D.J. Weber, and C.L. Geczy, "Functions of S100 proteins", Curr. Mol. Med., vol. 13, no. 1 , pp. 24-57, 2013.

[http://dx.doi.org/10.2174/156652413804486214] [PMID: 22834835]

[8] R. Donato, "S100ß protein, a damage-associated molecular pattern protein in the brain and heart, and beyond", Cardiovasc. Psychiatry Neurol., 2010.

[9] J.P. Zackular, W.J. Chazin, and E.P. Skaar, "Nutritional immunity: S100 proteins at the host-pathogen interface", J. Biol. Chem., vol. 290, no. 31, pp. 18991-18998, 2015. [http://dx.doi.org/10.1074/jbc.R115.645085] [PMID: 26055713]

[10] S. Korfias, G. Stranjalis, A. Papadimitriou, C. Psachoulia, G. Daskalakis, A. Antsaklis, and D.E. Sakas, "Serum S-100B protein as a biochemical marker of brain injury: a review of current concepts", Curr. Med. Chem., vol. 13, no. 30, pp. 3719-3731, 2006. [http://dx.doi.org/10.2174/092986706779026129] [PMID: 17168733] 
[11] W.S. Griffin, O. Yeralan, J.G. Sheng, F.A. Boop, R.E. Mrak, C.R. Rovnaghi, B.A. Burnett, A. Feoktistova, and L.J. Van Eldik, "Overexpression of the neurotrophic cytokine S100 beta in human temporal lobe epilepsy", J. Neurochem., vol. 65, no. 1, pp. 228-233, 1995. [http://dx.doi.org/10.1046/j.1471-4159.1995.65010228.x] [PMID: 7790864]

[12] D.B. Zimmer, and D.J. Weber, "The calcium-dependent interaction of S100B with its protein targets", Cardiovasc. Psychiatry Neurol., vol. 2010, p. 728052, 2010. [http://dx.doi.org/10.1155/2010/728052] [PMID: 20827422]

[13] T. Yardan, A.K. Erenler, A. Baydin, K. Aydin, and C. Cokluk, Review article usefulness of S100 $\beta$ protein in neurological disorders structure and functions of $\mathrm{S} 100 \beta$ protein : Measurement of $\mathrm{S} 100 \beta$ protein : S100 $\beta$ as a marker in neurologic disorders : vol. 61, pp. 1-3, 2011.

[14] W.W. Streicher, M.M. Lopez, and G.I. Makhatadze, "Modulation of quaternary structure of S100 proteins by calcium ions", Biophys. Chem., vol. 151 , no. 3 , pp. 181-186, 2010.

[http://dx.doi.org/10.1016/j.bpc.2010.06.003] [PMID: 20621410]

[15] C. Adami, G. Sorci, E. Blasi, A.L. Agneletti, F. Bistoni, and R. Donato, "S100B expression in and effects on microglia", Glia, vol. 33, no. 2, pp. 131-142, 2001. [http://dx.doi.org/10.1002/1098-1136(200102)33:2<131::AID-GLIA1012>3.0.CO;2-D] [PMID: 11180510]

[16] D. Kligman, and D.C. Hilt, "The S100 protein family", Trends Biochem. Sci., vol. 13, no. 11, pp. 437-443, 1988. [http://dx.doi.org/10.1016/0968-0004(88)90218-6] [PMID: 3075365]

[17] T. Ostendorp, J. Diez, C.W. Heizmann, and G. Fritz, "Biochimica et biophysica acta the crystal structures of human S100 $\beta$ in the zinc- and calcium-loaded state at three $\mathrm{pH}$ values reveal zinc ligand swapping BBA - Mol", Cell Res., vol. 1813, no. 5, pp. 1083-1091, 2011. [PMID: 20950652]

[18] D. Seeliger, and B.L. de Groot, "Ligand docking and binding site analysis with PyMOL and Autodock/Vina", J. Comput. Aided Mol. Des., vol. 24 , no. 5 , pp. 417-422, 2010. [http://dx.doi.org/10.1007/s10822-010-9352-6] [PMID: 20401516]

[19] P. Scarborough, "Stroke statistics 2009 edition", Br. Hear. Found., 2009.

[20] G.A. Donnan, M. Fisher, M. Macleod, and S.M. Davis, "Stroke", Lancet, vol. 371, no. 9624, pp. 1612-1623, 2008. [http://dx.doi.org/10.1016/S0140-6736(08)60694-7] [PMID: 18468545]

[21] H. Haimoto, S. Hosoda, and K. Kato, "Differential distribution of immunoreactive S100-alpha and S100-beta proteins in normal nonnervous human tissues", Lab. Invest., vol. 57, no. 5, pp. 489-498, 1987. [PMID: 3316838]

[22] J.G. Sheng, R.E. Mrak, C.R. Rovnaghi, E. Kozlowska, L.J. Van Eldik, and W.S. Griffin, "Human brain S100 beta and S100 beta mRNA expression increases with age: pathogenic implications for Alzheimer's disease", Neurobiol. Aging, vol. 17, no. 3, pp. 359-363, 1996. [http://dx.doi.org/10.1016/0197-4580(96)00037-1] [PMID: 8725896]

[23] A. Amadei, I. Daidone, A. Di Nola, and M. Aschi, "Theoretical-computational modelling of infrared spectra in peptides and proteins: a new frontier for combined theoretical-experimental investigations", Curr. Opin. Struct. Biol., vol. 20, no. 2, pp. 155-161, 2010. [http://dx.doi.org/10.1016/j.sbi.2010.01.001] [PMID: 20116996]

[24] E. Lindahl, B. Hess, and D. van der Spoel, "GROMACS 3.0: A package for molecular simulation and trajectory analysis", J. Mol. Model., vol. 7, no. 8, pp. 306-317, 2001. [http://dx.doi.org/10.1007/s008940100045]

[25] Z. Fakhar, S. Naiker, C.N. Alves, T. Govender, G.E. Maguire, J. Lameira, G. Lamichhane, H.G. Kruger, and B. Honarparvar, "A comparative modeling and molecular docking study on Mycobacterium tuberculosis targets involved in peptidoglycan biosynthesis", J. Biomol. Struct. Dyn., vol. 34, no. 11, pp. 2399-2417, 2016. [http://dx.doi.org/10.1080/07391102.2015.1117397] [PMID: 26612108]

[26] R. Hühne, F-T. Koch, and J. Sühnel, "A comparative view at comprehensive information resources on three-dimensional structures of biological macro-molecules", Brief. Funct. Genomics Proteomics, vol. 6, no. 3, pp. 220-239, 2007. [http://dx.doi.org/10.1093/bfgp/elm020] [PMID: 17956938]

[27] A. D. Astuti, and A. B. Mutiara, "Performance analysis on molecular dynamics simulation of proteinusing rOMACS", arXiv Prepr. arXiv0912.0893, 2009.

[28] A. Verma, G. Culbertson, and K. Ramani, "Chiron", In: Proceedings of the extended abstracts of the 32nd annual ACM conference on Human factors in computing systems - CHI EA '14, 2014, pp. 1831-1836. [http://dx.doi.org/10.1145/2559206.2581161]

[29] H. Land, and M.S. Humble, "YASARA: A tool to obtain structural guidance in biocatalytic investigations", Methods Mol. Biol., vol. 1685, pp. 43-67, 2018. [http://dx.doi.org/10.1007/978-1-4939-7366-8_4] [PMID: 29086303]

[30] S. Zheng, Q. Tang, J. He, S. Du, S. Xu, C. Wang, Y. Xu, and F. Lin, "VFFDT: A New Software for Preparing AMBER Force Field Parameters for Metal-Containing Molecular Systems", J. Chem. Inf. Model., vol. 56, no. 4, pp. 811-818, 2016. [http://dx.doi.org/10.1021/acs.jcim.5b00687] [PMID: 26998926]

[31] D.A. Case, T.E. Cheatham III, T. Darden, H. Gohlke, R. Luo, K.M. Merz Jr, A. Onufriev, C. Simmerling, B. Wang, and R.J. Woods, "The Amber biomolecular simulation programs", J. Comput. Chem., vol. 26, no. 16, pp. 1668-1688, 2005. 
[http://dx.doi.org/10.1002/jcc.20290] [PMID: 16200636]

[32] R.M.C. Published, A. Url, P. Microarrays, O. Source, and P.A.A. Sequences, "Bioinformatics tools for protein analysis", Analysis, vol. 2, no. 4, pp. 1-4, 2005.

[33] Y.F. Lin, C.W. Cheng, C.S. Shih, J.K. Hwang, C.S. Yu, and C.H. Lu, "MIB: Metal ion-binding site rediction and docking server", J. Chem. Inf. Model., vol. 56, no. 12, pp. 2287-2291, 2016. [http://dx.doi.org/10.1021/acs.jcim.6b00407] [PMID: 27976886]

[34] N.M. O’Boyle, M. Banck, C.A. James, C. Morley, T. Vandermeersch, and G.R. Hutchison, "Open babel: An open chemical toolbox", J. Cheminform., vol. 3, no. 10, p. 33, 2011.

[http://dx.doi.org/10.1186/1758-2946-3-33] [PMID: 21982300]

[35] IBM, "IBM SPSS advanced statistics 20", Ibm, p. 184, 2012.

[36] O. Carugo, "Statistical validation of the root-mean-square-distance, a measure of protein structural proximity", Protein Eng. Des. Sel., vol. 20, no. 1 , pp. 33-37, 2007.

[http://dx.doi.org/10.1093/protein/gzl051] [PMID: 17218333]

[37] C.N. Pace, "Energetics of protein hydrogen bonds", Nat. Struct. Mol. Biol., vol. 16, no. 7, pp. 681-682, 2009. [http://dx.doi.org/10.1038/nsmb0709-681] [PMID: 19578376]

[38] C. Chakraborty, and A. Agrawal, "Computational analysis of C-reactive protein for assessment of molecular dynamics and interaction properties", Cell Biochem. Biophys., vol. 67, no. 2, pp. 645-656, 2013. [http://dx.doi.org/10.1007/s12013-013-9553-4] [PMID: 23494263]

[39] E. Durham, B. Dorr, N. Woetzel, R. Staritzbichler, and J. Meiler, "Solvent accessible surface area approximations for rapid and accurate protein structure prediction", J. Mol. Model., vol. 15, no. 9, pp. 1093-1108, 2009. [http://dx.doi.org/10.1007/s00894-009-0454-9] [PMID: 19234730]

[40] B.R. Dempsey, and G.S. Shaw, "Identification of calcium-independent and calcium-enhanced binding between S100B and the dopamine D2 receptor", Biochemistry, vol. 50, no. 42, pp. 9056-9065, 2011. [http://dx.doi.org/10.1021/bi201054x] [PMID: 21932834]

(C) 2018 Tiburu et al.

This is an open access article distributed under the terms of the Creative Commons Attribution 4.0 International Public License (CC-BY 4.0), a copy of which is available at: https://creativecommons.org/licenses/by/4.0/legalcode. This license permits unrestricted use, distribution, and reproduction in any medium, provided the original author and source are credited. 